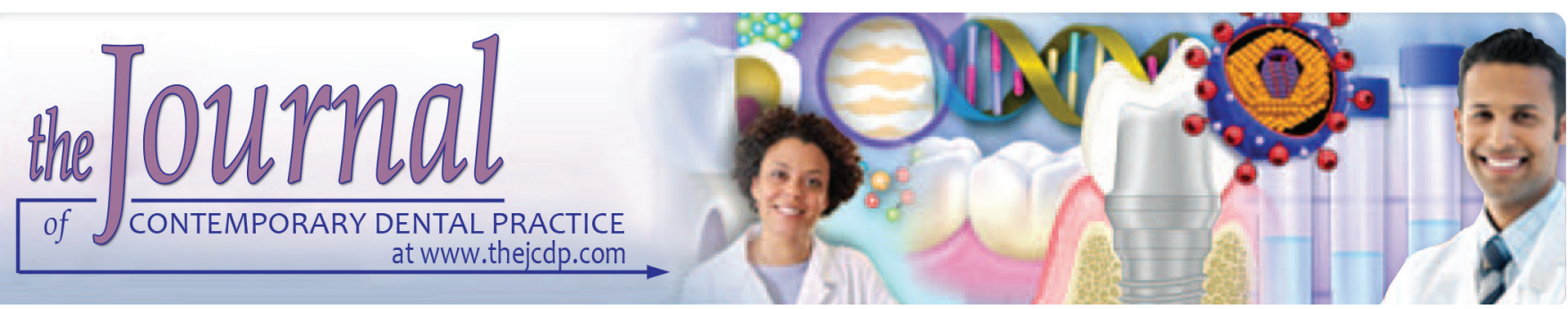

\title{
Effectiveness of Mentha piperita Leaf Extracts against Oral Pathogens: An in vitro Study
}

\author{
${ }^{1}$ Rekha Raghavan, ${ }^{2}$ MP Shyamala Devi, ${ }^{3}$ Megha Varghese, ${ }^{4}$ Ajesh Joseph, ${ }^{5}$ Sanupa S Madhavan \\ ${ }^{6}$ Pochappallil V Sreedevi
}

\begin{abstract}
Aim: The study aims to assess the Mentha piperita leaf extract's effectiveness against oral pathogens.

Materials and methods: The leaf extract of $M$. piperita was prepared using cold water method. The three microbial strains, i.e., Streptococcus mutans, Aggregatibacter actinomycetemcomitans, and Candida albicans were used as microbiological materials. Chlorhexidine $0.2 \%$ was used as positive control. The digital caliper was used to measure the zone of inhibition to know the antimicrobial activity at 24 and 48 hours. To compare the activity within and between the different microbial strains, one-way analysis of variance (ANOVA) was used. To analyze the data, Statistical Package for the Social Sciences (SPSS) software version of 21.0 was used. The $p$-value $<0.05$ was considered as statistically significant.
\end{abstract}

Results: Maximum inhibition zone was seen in both M. piperita extracts and $0.2 \%$ chlorhexidine with S. mutans at 24 and 48 hours, followed by $A$. actinomycetemcomitans, and $C$. albicans respectively. The statistical analysis ANOVA reveals the statistically significant association of $M$. piperita extracts with $p$-value $<0.001$. The comparison with $0.2 \%$ chlorhexidine at 24 hours showed a p-value of $<0.04$ and at 48 hours, it showed a p-value $<0.001$, which was statistically significant.

Conclusion: The present study concluded that $M$. piperita showed antimicrobial activity against the oral microorganisms which are causing major less or more severe oral diseases

\footnotetext{
${ }^{1,4}$ Department of Periodontology, Educare Institute of Dental Sciences, Malappuram, Kerala, India

${ }^{2,3}$ Department of Periodontology, P.S.M. College of Dental Science \& Research, Thrissur, Kerala, India

${ }^{5}$ Department of Periodontology, Sree Anjaneya Institute of Dental Sciences, Kozhikode, Kerala, India

${ }^{6}$ Department of Conservative Dentistry and Endodontics, P.S.M. College of Dental Science \& Research, Thrissur, Kerala, India

Corresponding Author: Rekha Raghavan, Department of Periodontology, Educare Institute of Dental Sciences Malappuram, Kerala, India, Phone: +919349118552, e-mail: raghavan.rekha8@gmail.com
}

and it can be administered as an alternative medicine for the conventional treatment.

Clinical significance: The study results serve as a guide in selecting and providing information about the efficacy of M. piperita extracts to the dental professionals. The discovery of a potential herbal medication would be a great development in the field of antimicrobial therapies.

Keywords: Antimicrobial activity, Mentha piperita, Oral pathogen, Zone of inhibition.

How to cite this article: Raghavan R, Devi MPS, Varghese M, Joseph A, Madhavan SS, Sreedevi PV. Effectiveness of Mentha piperita Leaf Extracts against Oral Pathogens: An in vitro Study. J Contemp Dent Pract 2018;19(9):1042-1046.

Source of support: Nil

Conflict of interest: None

\section{INTRODUCTION}

The major issue worldwide in health care field is the oral disease. The issues include tooth loss, periodontal diseases, orofacial disorders, and dental caries. These are some of the diseases among the important oral health issues. Some of them may cause health concerns which are significant. $^{1}$

Evidences which are associated with oral health and chronic conditions are considered, such as the association of poor oral health and aggressive periodontal diseases with that of the systemic diseases, such as lung disease, osteoporosis, strokes, rheumatoid arthritis, diabetes, heart attack, and other cardiovascular diseases. ${ }^{2}$ In addition to it, periodontal disease may also cause complication during pregnancy, such as preterm low birth weight. In adult patients, $20 \%$ of the tooth loss is mainly due to poor periodontal health, resulting in significant morbidity and may lead to premature death. ${ }^{3}$

The ancient custom followed around the world is the use of oral care agents made up of herbal products. As an alternative to the expensive antibiotics and their side 
effects, plant remedies are recognized as the important alternatives by the scientists. ${ }^{4}$

The peppermint (botanical name: Mentha piperita), member of Lamiaceae, a large mint family, is a perennial herb which grows fast and can reach up to $1.5 \mathrm{~m}$ height under favorable conditions. The extremely variable species M. piperita is distributed around Mediterranean region, eastward into Asia and in Europe. In India, minor sore throat and irritation of the throat or minor mouth are treated with peppermint leaves. It is used in the treatment of minor sprains and aches and used as a nasal decongestant. In addition, it has antiseptic, antiparasitic, carminative, and stimulant properties. ${ }^{5}$

Considering all these properties, to assess the effectiveness of leaf extracts of $M$. piperita against three oral microorganisms, such as C. albicans, A. actinomycetemcomitans, and S. mutans, an in vitro study was conducted.

\section{MATERIALS AND METHODS}

The present in vitro study was conducted at the Department of Periodontology, Educare Institute of Dental Sciences, Kerala, India.

\section{Collection of Leaf}

Matured, disease-free, healthy leaves of $M$. piperita were collected from the local garden directly. The leaves were washed under tap water and are cleaned in the research laboratory of the Department of Microbiology. The leaves were chopped into small pieces, air dried for 7 days, at room temperature. The dried leaves were finely powered using blender machine.

\section{Cold Water Extract Method}

The crude preparation was done using a conical flask; 15 gm of powder was mixed in $100 \mathrm{~mL}$ of distilled water (cold water extract) and was left overnight inside the shaker

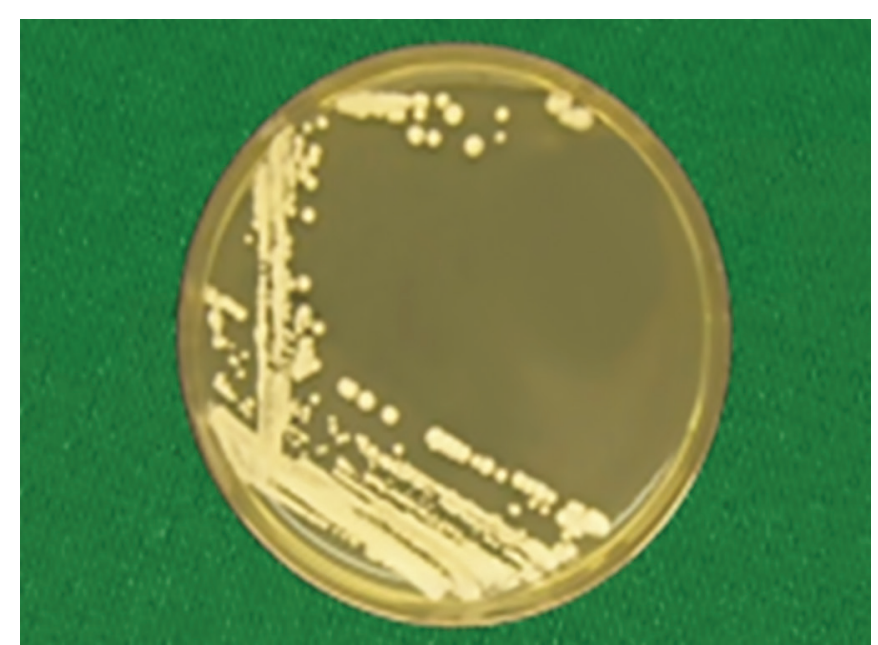

Fig. 1: Zone of inhibition of C. albicans at $35^{\circ} \mathrm{C}$. The preparation was centrifuged at $2500 \mathrm{rpm}$ for 10 minutes. The centrifuged product was transferred in to a preweighed beaker. The supernatant plant extract was concentrated by evaporating the solvent at $60^{\circ} \mathrm{C}$. The weighed crude extract was dissolved in dimethyl sulfoxide of known volume. The sterilized final concentration was filtered through Millipore filters $(0.45 \mu \mathrm{m})$. The extracts in aqueous form were stored at $4^{\circ} \mathrm{C}$ in sample bottles prior to use. ${ }^{6}$

\section{Strains used}

Three microbial strains, such as S. mutans, A. actinomycetemcomitans, and C. albicans which mainly cause more or less oral infections of severe intensity were collected from Sudharma Metropolis, Thrissur.

\section{Disk Diffusion Method}

To determine the bacterial growth inhibition by plant extract, the disk diffusion method is used. ${ }^{7}$ In this method, the disks were aseptically placed over the bacterial culture of agar-nutrient plates incubated for 24 hours at $37^{\circ} \mathrm{C}$. A digital Vernier caliper was used to measure the zones of inhibition around the disk after inoculation.

\section{Evaluation of Antimicrobial Activity}

The disk diffusion method will determine the efficacy of $M$. piperita leaf extract to inhibit the formation of new bacterial and fungal colonies by forming an inhibitory zone. Candida albicans was suspended in sterile saline of $2 \mathrm{~mL}$, and each bacterium was suspended under peptone water of $2 \mathrm{~mL}$. The turbidity of the suspension was set to $0.5 \mathrm{McF}$ arland standard using turbidimeter. A lawn was created on Sabouraud dextrose agar (C. albicans) (Fig. 1) and Mueller-Hinton blood agar medium (S. mutans and A. actinomycetemcomitans) (Figs 2 and 3) plates using the sterile cotton swab dipped in the suspension. Using

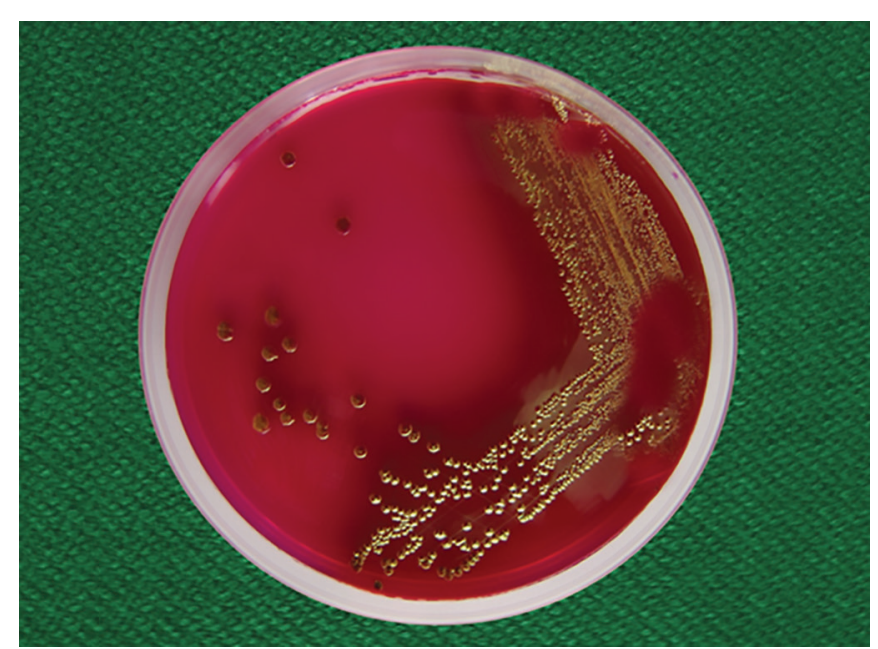

Fig. 2: Zone of inhibition of S. mutans 


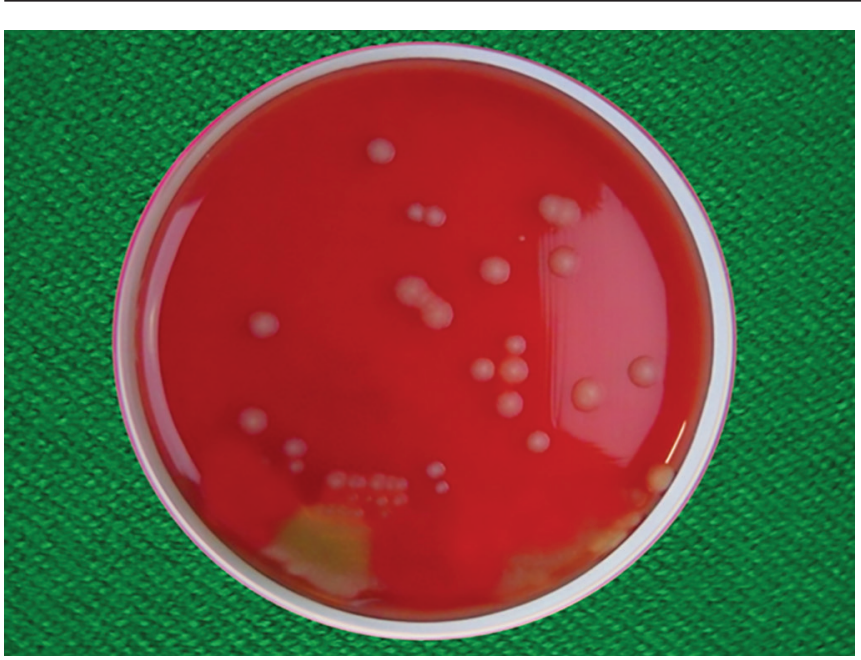

Fig. 3: Zone of inhibition of $A$. actinomycetemcomitans

sterile forceps, the sterile disks were impregnated with M. piperita leaf extract of $80 \mu \mathrm{L}$ and were applied on the agar surface. The agar plates were incubated at $37^{\circ} \mathrm{C}$. And $0.2 \%$ chlorhexidine used as positive control. The zone of inhibition was measured at 24 to 48 hours in millimeters, using a digital caliper.

\section{Statistical Analysis}

The analysis of the results was done by calculating mean and standard deviation (SD) using the SPSS software version 21.0. To compare within and between microbial strains, one-way ANOVA was used. The data with a significance level of $p<0.05$ are statistically significant.

Table 1: Mean zone of inhibition of $M$. piperita extracts against oral pathogens at 24 hours

\begin{tabular}{lll}
\hline & \multicolumn{2}{c}{$\begin{array}{c}\text { Mean of zone of inhibition } \\
\text { (in millimeters) }\end{array}$} \\
\cline { 2 - 3 } Microorganism & $\begin{array}{l}\text { M. piperita } \\
\text { extracts }\end{array}$ & $\begin{array}{l}0.2 \% \\
\text { chlorhexidine }\end{array}$ \\
\hline S. mutans & $20.16 \pm 0.36$ & $32.64 \pm 1.34$ \\
A. actinomycetemcomitans & $18.34 \pm 1.09$ & $28.45 \pm 0.22$ \\
C. albicans & $15.83 \pm 1.37$ & $27.66 \pm 1.85$ \\
\hline
\end{tabular}

\section{RESULTS}

The mean zone of inhibition of $M$. piperita extracts at 24 hours against oral pathogens is shown in Table 1 . The maximum zone of inhibition with both $M$. piperita extracts and $0.2 \%$ chlorhexidine was seen with $S$. mutans $(20.16 \pm$ 0.36 and $32.64 \pm 1.34$ ), followed by A. actinomycetemcomitans $(18.34 \pm 1.09$ and $28.45 \pm 0.22)$ and C. albicans (15.83 \pm 1.37 and $27.66 \pm 1.85)$.

The mean zone of inhibition of $M$. piperita extracts at 48 hours against oral pathogens is shown in Table 2 . The maximum zone of inhibition with both $M$. piperita extracts and $0.2 \%$ chlorhexidine was seen with $S$. mutans $(34.18 \pm$ 1.46 and $40.11 \pm 0.98)$, followed by $A$. actinomycetemcomitans $(30.48 \pm 1.82$ and $37.76 \pm 1.78)$ and C. albicans $(28.75$ \pm 2.57 and $33.62 \pm 1.54)$.

The comparison of the mean zone of inhibition at 24 and 48 hours with $M$. piperita extracts is shown in Tables 3 and 4 . The analysis of covariance showed a highly statistical significant association at 48 hours with p-value $<0.001$.

The comparison of the mean zone of inhibition at 24 and 48 hours with positive control is shown in Tables 5 and 6. The analysis of covariance showed a statistically significant association at 24 and 48 hours with p-value less than 0.04 and 0.001 respectively.

\section{DISCUSSION}

Increase in the antibiotic resistance and its side effects has led the researchers to suggest the plant extracts as an alternative for the treatment of voracious infectious diseases. ${ }^{8}$

Table 2: Mean zone of inhibition of $M$. piperita extracts against oral pathogens at 48 hours

\begin{tabular}{lll}
\hline & \multicolumn{2}{c}{$\begin{array}{c}\text { Mean of zone of inhibition } \\
\text { (in millimeters) }\end{array}$} \\
\cline { 2 - 3 } Microorganism & $\begin{array}{l}\text { M. piperita } \\
\text { extracts }\end{array}$ & $\begin{array}{l}0.2 \% \\
\text { chlorhexidine }\end{array}$ \\
\hline S. mutans & $34.18 \pm 1.46$ & $40.11 \pm 0.98$ \\
A. actinomycetemcomitans & $30.48 \pm 1.82$ & $37.76 \pm 1.78$ \\
C. albicans & $28.75 \pm 2.57$ & $33.62 \pm 1.54$ \\
\hline
\end{tabular}

Table 3: Comparison of mean zone of inhibition with $M$. piperita extracts after 24 hours

\begin{tabular}{llllll}
\hline Extract & Microorganism & Mean $\pm S D$ & Standard error & $f$-value & $p$-value \\
\hline M. piperita extracts & S. mutans & $20.16 \pm 0.36$ & 0.1742 & 64.520 & 0.08 \\
& A. actinomycetemcomitans & $18.34 \pm 1.09$ & 0.2260 & & \\
& C. albicans & $15.83 \pm 1.37$ & 0.0890 & & \\
\hline
\end{tabular}

Table 4: Comparison of mean zone of inhibition with $M$. piperita extracts after 48 hours

\begin{tabular}{llllll}
\hline Extract & Microorganism & Mean $\pm S D$ & Standard error & $f$-value & $p$-value \\
\hline M. piperita extracts & S. mutans & $34.18 \pm 1.46$ & 0.0054 & 58.164 & 0.001 \\
& A. actinomycetemcomitans & $30.48 \pm 1.82$ & 0.6879 & & \\
& C. albicans & $28.75 \pm 2.57$ & 0.1752 & & \\
\hline
\end{tabular}


Effectiveness of Mentha piperita Leaf Extracts against Oral Pathogens

Table 5: Comparison of mean zone of inhibition with positive control after 24 hours

\begin{tabular}{llllll}
\hline Extract & Microorganism & Mean \pm SD & Standard error & $f$-value & $p$-value \\
\hline $0.2 \%$ chlorhexidine & S. mutans & $32.64 \pm 1.34$ & 0.0211 & 73.683 & 0.04 \\
& A. actinomycetemcomitans & $28.45 \pm 0.22$ & 0.1532 & & \\
& C. albicans & $27.66 \pm 1.85$ & 0.1332 & & \\
\hline
\end{tabular}

Table 6: Comparison of mean zone of inhibition with positive control after 48 hours

\begin{tabular}{llllll}
\hline Extract & Microorganism & Mean \pm SD & Standard error & $f$-value & $p$-value \\
\hline $0.2 \%$ chlorhexidine & S. mutans & $40.11 \pm 0.98$ & 0.1773 & 69.546 & 0.001 \\
& A. actinomycetemcomitans & $37.76 \pm 1.78$ & 0.0034 & & \\
& C. albicans & $33.62 \pm 1.54$ & 0.2908 & & \\
\hline
\end{tabular}

Mentha piperita is a good antibacterial, antiseptic, and antiviral agent. It is clean, light, and has a refreshing aroma; it is a good insect repellant. It has a strengthening and stimulating effect used in the treatment of shock, neuralgia, and as a relief agent in general debility, migraines, and headaches. Its antispasmodic and antiseptic effect helps to reduce sinusitis, throat infections, flu, asthma, cold, bronchitis, mucus, and in relieving coughs. It is used as inhalants, applicants, or bathing agents. ${ }^{9}$ It has cleansing and cooling effect to soothe itchy skin and relieve inflammation. The peppermint property gives the mouth fresh feel, adds taste to the formula and also increases salivation which helps in dry mouth condition resulting in halitosis. ${ }^{10}$

The cold water leaf extract used in this study was similar to the Zamin et $\mathrm{al}^{11}$ study, which suggested that cold water $M$. piperita leaf extract has broad-spectrum antimicrobial activity, though the degree of vulnerability may differ within different microorganisms. This antimicrobial activity is found to prove the presence of secondary metabolites either in combination with various chemical compositions or individual component of a plant.

Aggregatibacter actinomycetemcomitans showed the zone of inhibition more than C. albicans and less than that of $S$. mutans at 24 and 48 hours, which is similar to that of Karicheri and Antony ${ }^{4}$ study, which showed that A. actinomycetemcomitans demonstrated antibacterial property out of 68 strains using disk diffusion method; 53 (77.9\%) were sensitive against $M$. piperita and 52 (76.5\%) were sensitive against $M$. arvensis oil.

Chlorhexidine $0.2 \%$ was used as a positive control in the present study. It is similar to Balagopal and Arjunkumar ${ }^{12}$ and Mathur et $\mathrm{al}^{13}$ studies, which mention about the chlorhexidine formulations which are considered as gold standard anti-gingivitis and antiplaque mouth rinses due to their extended broad-spectrum activity toward microorganisms and plaque-inhibitory potential.

Candida albicans showed the minimum zone of inhibition in the current study, similar to that of Doddanna et $\mathrm{al}^{14}$ study, which stated that few extracts of plant, such as onion bulb and leaves, curry leaves, tea leaves, and aloe vera, which have medicinal values, are screened to evaluate their antimicrobial activity against $C$. albicans. Candida albicans were strongly repressed by the alcoholic curry leaves followed by the aqueous tea leaves. The alcoholic mint leaves, alcoholic aloe vera, alcoholic onion bulb, alcoholic tea leaves, and alcoholic onion leaves are known to inhibit the C. albicans' growth in increasing order, but are not as strong as above-mentioned extracts.

A good antibiofilm activity was exhibited by M. piperita against gram-positive pathogens, L. monocytogenes as per Sandasi et al. ${ }^{15}$ Mentha piperita's organic leaf extracts showed its wide range of broad-spectrum antibacterial activity as stated by Bupesh et al. ${ }^{16}$ These activities are attributed to the presence of potential compounds including menthone, menthofuran, menthyl acetate, and menthol. Menthol alone has been proved to inhibit the organisms, such as bacteria, viruses, and fungi which contribute to the overall antimicrobial activity of the plant extract of $M$. piperita.

The compounds of $M$. piperita that were investigated by Baratta et $\mathrm{al}^{17}$ proved to have antimicrobial activity and they suggested that the leaf extract of M. piperita contains the active component which is effectively responsible for eradicating the pathogens.

The data proved that the herbal leaf extract exhibits variation in the effectiveness of their antimicrobial property against microorganisms which are tested. Considering the limitation of the in vitro studies, it is necessary to mention that these results may alter in in vivo analysis because the environment tested will differ from that of the oral cavity. Therefore, in vitro studies are necessary to support further clinical investigations. The result from this study can provide the information to the dental professionals regarding the efficacy of the M. piperita leaf extract and acts as a supporting document for further studies on $M$. piperita.

The low effectiveness, high cost, and toxicity of the recent antimicrobial agents available in the market make 
it inefficient. The discovery of potent plant medication will be a great development in the line of antimicrobial therapies. This shows a need to develop new antimicrobial agents which can satisfy the current demand.

\section{CONCLUSION}

The present study concluded that M. piperita has been proved to have antimicrobial activity against oral microorganisms and can be used as an alternative medicine and as an adjunct to the conventional therapy, which would help the countries which are developing and having financial constraints and with limited oral health care facility for the concerned population.

\section{REFERENCES}

1. Borhan-Mojabi, K.; Azimi, S. Antimicrobial natural products in oral health. In: Méndez-Vilas A, editor. Microbial pathogens and strategies for combating them: science, technology and education. Spain: FORMATEX; 2013. pp. 932-939.

2. Rautemaa R, Lauhio A, Cullinan MP, Seymour GJ. Oral infections and systemic disease-an emerging problem in medicine. Clin Microbiol Infect 2007 Nov;13(11):1041-1047.

3. Palombo EA. Traditional medicinal plant extracts and natural products with activity against oral bacteria: potential application in the prevention and treatment of oral diseases. Evid Based Complement Alternat Med 2011;2011:680354.

4. Karicheri R, Antony B. Antibacterial and antibiofilm activities of peppermint (Mentha piperita linn) and menthol mint (mentha arvensis linn) essential oils on aggregatibacter actinomycetemcomitans isolated from orodental infections. EJPMR 2016 Jul;3(7):577-581.

5. Mathur A, Prasad GB, Rao N, Babu P, Dua VK. Isolation and identification of antimicrobial compound from Mentha piperita $L$. Rasayan J Chem 2011 Jan;4(1):36-42.

6. Al-Sum BA, Al-Arfaj AA. Antimicrobial activity of the aqueous extract of mint plant. Sci J Clin Med 2013 Jun;2(3):110-113.
7. Nostro AM, Germano P, D'Angelo V, Mariko A, Cannatelli MA. Extraction methods and bioautography for evaluation of medicinal plant antimicrobial activity. Lett Appl Microbiol 2000 May;30(5):379-384.

8. Okmen AS, Okmen G, Arslan A, Vurkun M. Antibacterial activities of Mentha piperita L. extracts against bacteria isolated from Soccer player's shoes and its antioxidant activities. IJPER 2017 Jul;51(3 Suppl):S163-S169.

9. Thosar N, Basak S, Bahadure RN, Rajurkar M. Antimicrobial efficacy of five essential oils against oral pathogens: an in vitro study. Eur J Dent 2013 Sep;7(Suppl 1):S71-S77.

10. Dawes C, Macpherson LM. Effects of nine different chewing gums and lozenges on salivary flow rate and $\mathrm{pH}$. Caries Res 1992 Feb;26(3):176-182.

11. Zamin I, Majid A, Ali I, Khan TA, Ibrar M, Shah JA, Ullah Z, Aman I, Naveed M, Khan I, et al. In-vitro antibacterial activity of Mentha piperita leaf extracts to some selective pathogenic bacterial strains. Int J Med Pharm Sci Res Rev 2013 Aug;1(2):1-13.

12. Balagopal S, Arjunkumar R. Chlorhexidine: the gold standard antiplaque agent. J Pharm Sci Res 2013 Dec;5(12):270-274.

13. Mathur S, Mathur T, Shrivastava R, Khatri R. Chlorhexidine: the gold standard in chemical plaque control. Natl J Physiol Pharm Pharmacol 2011 Jun;1(2):45-50.

14. Doddanna SJ, Patel S, Sundarrao MA, Veerabhadrappa RS. Antimicrobial activity of plant extracts on Candida albicans: an in vitro study. Indian J Dent Res 2013 Jul-Aug;24(4): 401-405.

15. Sandasi M, Leonard CM, Viljoen AM. The effect of five common essential oil components on Listeria monocytogenes biofilms. Food Control 2008 Nov;19(11):1070-1075.

16. Bupesh G, Amutha C, Nandagopal S, Ganeshkumar A, Sureshkumar P, Murali KS. Antibacterial activity of Mentha piperita L. (peppermint) from leaf extracts-a medicinal plant. Acta Agriculturae Slovenica 2007 Aug;89(1):73-79.

17. Baratta MT, Dorman HJ, Deans SG, Figueiredo AC, Barroso JG, Ruberto G. Antimicrobial and antioxidant properties of some commercial essential oils. Flavour Fragr J 1998 Jul-Aug;13(4):235-244. 